\title{
LA PINTURA DE CÉZANNE Y LA FENOMENOLOGÍA DE LA PERCEPCIÓN DE MERLEAU-PONTY COMO BÚSQUEDA DE LA EXPERIENCIA ORIGINARIA
}

Francisco Conde Soto

Universidad de Barcelona

\section{Introducción}

Este artículo pretende estudiar determinados aspectos teóricos del concepto de percepción que el pensador Merleau-Ponty y el pintor Cézanne comparten de forma no casual y digna de análisis. Su principal objetivo es esclarecer de dónde procede la coincidencia entre algunos de los rasgos principales de la caracterización del fenómeno de la percepción por parte de la fenomenología de Merleau-Ponty y la técnica pictórica de Cézanne, que puede ser objeto de una interpretación sumamente enriquecedora si se la considera bajo las consideraciones teóricas del pensador francés. Es cierto que los ámbitos de trabajo de ambas figuras son de naturaleza claramente distinta, puesto que uno pretende explícitamente elevar a reflexión el acto perceptivo, mientras que el otro rechaza explícitamente toda teorización acerca de la pintura y del peculiar modo de percepción que acompaña al artista durante el proceso de creación y al receptor de la obra durante su interpretación. Por otra parte, la diferente situación cronológica impide pensar en una influencia de las reflexiones de Merleau-Ponty sobre el proceder de Cézanne; sin embargo, si que es posible considerar que de su reflexión acerca de la obra del pintor el fenomenólogo hubiese podido extraer cierto espíritu general influyente en su obra. En todo caso, más allá de la voluntad explícita por parte del segundo de considerar la técnica pictórica del primero, resulta relevante que ambos sean impulsados por un mismo pathos. El hecho de que tras los planteamientos teóricos de uno y de la praxis pictórica del otro se encuentre una raíz común los vincula de manera innegable. En el caso de Merleau-Ponty su fenomenología pretende analizar la forma en qué se produce la relación sujeto-mundo apuntando a que ésta no es otra que una cierta "experiencia originaria", algunas de cuyas características 
intentaremos precisar en este artículo. Su análisis de la percepción desglosa una serie de rasgos relevantes que en último objeto apuntan a descubrir que la percepción del objeto estático es el resultado de todo un proceso mucho más primigenio y anterior. En el caso de Cézanne nos encontramos ante una comprensión del fenómeno pictórico que quiere recoger el aparecerse originario de las cosas tal y como se le ofrecería a una mirada que va más allá de las categorías cosificadoras de la percepción cotidiana. Libre de ellas la pintura debe plasmar todo el proceso del aparecerse previo al resultado ya culminado de la constitución. El pintor debe también atender a la experiencia originaria en la que se le ofrece el mundo y poner todo su empeño en plasmarla.

\section{La percepción según Merleau-Ponty}

No es intención ni cabe en la extensión de este estudio elaborar un repaso exhaustivo de la caracterización merleau-pontiana de la percepción, sino que su mucho más modesto objetivo es partir del análisis puntual de algunos de los rasgos con los que Merleau-Ponty caracteriza a la percepción en la segunda parte de la Fenomenología de la percepción. Lo que se pretende es poner de manifiesto como estos rasgos formaban parte de la visión y proceder pictóricos de Cézanne de manera al menos implícita. Concretamente, analizaremos algunas de las características recogidas en la segunda sección de la obra, titulada "El mundo percibido".

\subsection{La percepción se organiza como un campo}

Merleau-Ponty insiste en el hecho de que cada uno de los objetos de los diferentes actos perceptivos pertenece y se da siempre en el interior de un «campo» perceptivo y nunca de manera aislada. El objeto hacia el que se dirige nuestra atención se enmarca en una percepción previa del todo que lo rodea. La idea de base es que siempre percibimos mucho más de aquello a lo que atendemos. Sobre el marco general perceptivo se produce una selección posterior mediante la que fijamos el foco de nuestra atención en alguno de los puntos de ese campo. El resto permanece en un segundo plano a modo de trasfondo de ese objeto en el que nos centramos. La primera denominación técnica para ese trasfondo había sido acuñada ya en 1913 por Husserl mediante el conocido concepto de horizonte intencional. ${ }^{1}$ En su máxima expresión se trata del horizonte total que configura el mundo. En este horizonte se encuentran por una parte las percepciones actuales, pero también todo un horizonte configurado por aquellas percepciones sedimentadas ya realizadas, que aunque 
no sean estrictamente actuales todavía tienen valor (en alemán es expresado por Husserl de la siguiente forma: "sie gelten noch") y, por lo tanto, repercuten en la experiencia presente. Pero además también pertenecen a este horizonte aquellas percepciones potenciales futuras, que, aunque indeterminadas en cuanto a su contenido, reciben cierta concreción en la medida en que su estilo debe respetar el estilo general que hasta el momento han mostrado las percepciones acerca del mundo. ${ }^{2}$ La aparición del objeto se levanta sobre un trasfondo vago que es el resultado de la organización de unos elementos previos a él; desde este trasfondo surge el objeto percibido, organizándose con un grado de precisión que aumenta progresivamente. Se trata siempre de un trasfondo subyacente a la figura percibida, previo a la objetivación realizada por la atención, que sólo nos ofrece un objeto aislado y entresacado de ese su trasfondo. Lo mismo que acabamos de constatar con respecto a un objeto es aplicable a la percepción de una perspectiva singular de un objeto: cada una de las perspectivas de cualquier objeto que percibimos está también dentro de un sistema, en este caso, el generado por el conjunto denominado objeto.

Este "campo" del que estamos hablando posee una doble naturaleza: por una parte, como ya se ha dicho, se trata del entorno o fondo espacial sobre el que se conforma la figura del objeto de una percepción actual; pero además debe ser entendido como el resultado de una acumulación temporal, como el conjunto de sedimentaciones o intencionalidades que nuestro cuerpo ha ido atesorando a lo largo de percepciones anteriores y que son puestas en juego por él en cada nueva percepción. No hay un acercamiento neutral -“sin prejuicios"- al objeto, sino que cada percepción pone en juego toda la carga de sentido adquirida en las percepciones anteriores. De cara al posterior contraste con Cézanne es el primer tipo de "campo" el que resulta más relevante, puesto que se relaciona directamente con toda la problemática artística en torno a la relación entre el todo y las partes de la obra de arte.

\subsection{La percepción es un "flujo". La percepción del movimiento}

Según Merleau-Ponty, la consideración tradicional de que la percepción es percepción de objetos en cuanto cosas estáticas debe ser rechazada. Existe un fondo previo donde "las cosas se definen primero por su 'comportamiento' y no por unas 'propiedades estáticas" ". 3 Una descripción de los procesos perceptivos no debe partir nunca del análisis de las representaciones ya termi-

2 No podemos detenernos aquí para estudiar con mayor profundidad esta cuestión que pone en juego todo el problema de la relevancia de la temporalidad en la constitución de los objetos tal y como la comprende la fenomenología de Husserl. Los textos principales que deberían ser explicados para arrojar más luz en torno a este tema serían las lecciones sobre la conciencia interna del tiempo (Hay una excelente traducción castellana de Agustín Serrano de Haro, E. Husserl, Lecciones sobre la conciencia interna del tiempo, ed. Trotta, Madrid, 2001).

${ }^{3}$ M. Merleau-Ponty, Fenomenologia de la percepción, ed. Altaya, Barcelona, 1999, p. 290. 
nadas de los objetos, sino que su objeto es intentar captar aquella experiencia a partir de la que éstas son configuradas. La reflexión anterior se hace válida con todo rigor cuando se intentan comprender fenómenos como el del movimiento, que conducen a Merleau-Ponty a afirmar que el mundo no consiste en cosas, sino en cierta corriente lábil de experiencia fluida. "Si queremos tomarnos en serio el fenómeno del movimiento, hay que concebir un mundo que no esté hecho únicamente de cosas, sino de puras transiciones". ${ }^{4}$ La conclusión que se sigue necesariamente de lo anterior es que la percepción del movimiento no puede ser interpretada como el hecho de la ocupación de diferentes posiciones sucesivas por parte de un móvil. Tenemos constancia del movimiento sin necesidad de recurrir al establecimiento de propiedades objetivas o de cosas estables que en determinadas ocasiones están dotadas de movimiento. La percepción del movimiento no es la percepción de una propiedad de una cosa que está en movimiento, sino que nuestra captación originaria nos presenta un todo continuo móvil, en el que todavía no hay divisiones.

\subsection{Motricidad de la percepción. La percepción del color}

Otro de los rasgos bajo los que Merleau-Ponty concibe el fenómeno perceptivo es su carácter esencialmente motriz. Esto implica que por debajo de la diversidad de los datos de los sentidos (visual, auditivo, olfativo...) subsiste escondida una unidad común consistente en el hecho de que todos esos datos hacen referencia a una intencionalidad práxica del cuerpo. Bajo las informaciones que nos aporta cada sentido y como condición necesaria de cualquier percepción, existe una capacidad corporal, un fondo de potencialidad motriz del cuerpo que puede ser recogida en la afirmación de que el cuerpo es ante todo un cierto "yo puedo". Toda percepción tiene sus raíces en esta capa de motricidad originaria que aporta el propio cuerpo, de manera que las cualidades sensibles se aparecen a un cuerpo caracterizado esencialmente por consistir en un continuo "acompañamiento motor". El propio cuerpo se encuentra en comunión con las cosas, de forma que la cosa se presenta primero como un correlato para él y no como una significación que debiese ser captada por el entendimiento. Las cosas tienen significado porque el cuerpo contacta con ellas, porque hay una experiencia ante-predicativa en la que se produce un contacto primordial entre ambos polos. El cuerpo acoge en la percepción unas cosas cuya posibilidad de ser percibidas se asienta en el dirigirse motriz del cuerpo hacia ellas. Pero además, el hecho fundamental es que hay un compromiso existencial porque el que soy un cuerpo-en-un-mundo, que me ata a los objetos de manera primordial, que me coloca entre ellos antes de verlos como algo del ámbito del no-yo, externo y diferente a mí. 
Mi ojo es para mí un cierto poder de llegar a las cosas y no una pantalla en la que ellas se proyectan. La relación de mi ojo y del objeto no se me da bajo la forma de una proyección geométrica del objeto sin el ojo, sino como cierta presa del ojo en el objeto, aún vaga en la visión marginal, más pesada y precisa cuando miro fijamente el objeto. ${ }^{5}$

La percepción del color confirma de manera clara este carácter motriz de la percepción. Los colores tienen prịmariamente una significación motriz que afecta a nuestra manera de ser-en-el-mundo, que determina la forma en que se instaura el vínculo que nos sitúa inmediatamente entre las cosas: "El color, antes de ser visto, se anuncia por la experiencia de una cierta actitud del cuerpo que sólo a él conviene y que lo determina con precisión [...]". ${ }^{6}$ Cuando desde una interpretación intelectualista de corte cartesianizante se considera que la cosa consiste esencialmente en sus propiedades geométricas se olvida que las cualidades de color, dureza y peso ofrecen mucha más información sobre ella que el reconocimiento de su forma. El color que percibimos no es una cualidad objetivada, identificada físicamente y estabilizada como una determinada frecuencia de onda. El color se define esencialmente por permitir una directa "introducción en la cosa", 7 al tratarse de una estructura que inmediatamente identificamos como proveniente del objeto de forma directa.

Merleau-Ponty afirma que es mérito innegable de los pintores haber reconocido que en la naturaleza existen muy pocos colores y que lo que crea la gran variedad cromática está en relación con la diferente posición que el color ocupa en un todo en el que influyen también otros fenómenos, como la luminosidad, la forma de las figuras, el tipo de superficie... El carácter de campo de la percepción es el que hace que el fenómeno color deba ser considerado siempre en relación a un conjunto del que forman parte otros fenómenos. El valor de un color dentro de un cuadro se organiza según una lógica de grupo: "Más: hay una lógica total del cuadro o del espectáculo, una coherencia experimentada de los colores, de las formas espaciales y del sentido del objeto". 8 Además es especialmente interesante insistir en que no existe originariamente algo así como un color único-en-sí (rojo, verde...) que se manifiesta en repetidas ocasiones, sino que la percepción originaria del color ofrece una región luminosa dependiente de la superficie en la que se aparece. Con otras palabras, el color precede al objeto al que se adhiere y en consecuencia no puede ser interpretado como un rasgo o cualidad secundarios que se aparecen una vez terminada la constitución del objeto como figura. El color no es un elemento que sea percibido con independencia de aquello en lo que se aparece, sino que

5 Op. Cit., p. 294.

6 Op. Cit., p. 226.

7 Op. Cit., p. 319.

${ }^{8}$ Op. Cit., p. 326. 
su percepción se ofrece dentro de un todo en el que se entrelazan figura, tipo de superficie, etc.

\subsection{Crítica al intelectualismo: la experiencia originaria}

La descripción del fenómeno perceptivo por parte de Merleau-Ponty apunta a una crítica de todas aquellas interpretaciones que describen la percepción a partir de nuestra conciencia reflexiva a posteriori del fenómeno perceptivo. El establecimiento de la originariedad de la disociación entre sujeto y objeto, entre forma y materia, es considerado una ingenuidad, puesto que ignora la existencia de un estrato originario previo no polarizado, indiviso. Se trata de una estructura fundamental a través de la que se hace patente el hecho de que somos sujetos caracterizados esencialmente por "una comunicación con el mundo más antigua que el pensamiento",, 9 una comunicación opaca a la reflexión y que rehuye la determinación sujeto-objeto inherente a toda la reflexión tradicional acerca de la percepción.

Esta comunicación permite que nuestro entorno perceptivo sea organizado inmediatamente sin necesidad de una explicitación de carácter más o menos científico acerca de los objetos de los que consta. Por ejemplo, es posible percibir un cubo antes de poseer una definición explícita del mismo en cuanto constructo geométrico dotado de estos y aquellos rasgos, porque el cubo se relaciona primeramente con las posibilidades motrices de nuestro cuerpo. En el proceso perceptivo no hay nada así como un reconocimiento analítico de propiedades como paso previo a la identificación de un objeto, sino que el objeto tiene una fisonomía particular captada por el cuerpo que es anterior al establecimiento de cualquier caracterización bajo la forma de un listado de rasgos. Merleau-Ponty toma como representante de la teoría de la percepción científica a Kant, criticándole que no se haya interrogado acerca de la experiencia que subyace a la categorización espacio-temporal de la sensibilidad.

La conciencia perceptiva no nos da la percepción como una ciencia, la magnitud y la forma del objeto como leyes; y las determinaciones numéricas de la ciencia vuelven a pasar sobre el punteado de una constitución del mundo ya hecha con anterioridad a ellas. Kant, como el sabio, da por supuestos los resultados de esta experiencia precientífica, y solamente puede obviarla porque los utiliza. $^{10}$

Desde una perspectiva intelectualista se niega la existencia de cualquier capa de sentido anterior a aquella en la que se produce el establecimiento de 
propiedades objetivas o, en todo caso, se admite tan sólo la posibilidad de que haya un nivel previo de sensación puramente fisiológico, ajeno a toda constitución de sentido. Si se niega la constitución de sentido a un nivel previo a aquel donde la percepción es cosificada e interpretada siempre como percepción de cosas, todo ello es porque esta capa no puede ser pensada bajo las categorías que el pensamiento reflexivo emplea. El análisis intelectualista de la percepción es superficial porque parte de la decisión explícita de olvidar la experiencia originaria que está en el origen. Merleau-Ponty apunta que tanto el juicio como todas las restantes operaciones del entendimiento son procesos fundados sobre un acto perceptivo originario. ${ }^{11}$ Las denominaciones que Merleau-Ponty emplea para referirse a esta experiencia primera son varias. Se trata de un "lenguaje mudo" o una "lógica sin palabras", una "lógica vivida" o una "significación inmanente" de la percepción, que son previas a todo pensamiento objetivista. Para descubrir esta significación es necesario proceder a un análisis de la vivencia del mundo, de la experiencia en la que se aparecen las cosas previamente a la sedimentación y cosificación bajo la que nos la ofrece el pensamiento de carácter cientificista. Una fenomenología consciente de dónde se sitúan los puntos claves de su tarea debe esforzarse por la recuperación de esta experiencia originaria, siendo al mismo tiempo consciente de que esta capa no puede ser captada de manera absoluta y sin que permanezcan restos esencialmente inaprehensibles a la reflexión.

El nivel primordial está en el horizonte de todas nuestras percepciones, pero de un horizonte que, por principio, nunca puede ser alcanzado y tematizado en una percepción expresa. Cada uno de los niveles en los que vivimos va apareciendo uno tras otro cuando echamos el ancla en un "medio contextual" que a nosotros se propone. ${ }^{12}$

La fenomenología, en cuanto descripción de esta experiencia, se convierte así en el intento denodado por recoger de la forma más fidedigna posible sus contenidos y la forma en que se muestra "primitivamente" el mundo.

\subsection{EI lenguaje}

Si aquí hacemos algunas anotaciones en torno a la concepción del lenguaje ello es así porque la pintura viene a ser también una manifestación regulada por unas normas que en su conjunto configuran lo que se conoce como lenguaje artístico. No se trata de elaborar aquí concienzudamente los nota-

11 Incluso hablar de un "acto" perceptivo puede ser engañoso si tras este término entendemos que hay una disociación entre acto y objeto. Debería hablarse más bien de una "vivencia" unitaria en la que se produce el quiasma inicial de contacto entre el cuerpo y lo real. 
bles apuntes del fenomenólogo francés en torno al lenguaje, sino en sentar las bases de una primera presentación de su concepción fundamental del lenguaje. Merleau-Ponty apunta la necesidad de un cambio en las teorías predominantes de forma que se abandone el presupuesto de que cada vocablo es un envoltorio inerte que viene a recubrir una experiencia previa. ${ }^{13}$ La palabra no efectúa la traducción de un pensamiento ya hecho, sino que viene a "consumar" este pensamiento. ${ }^{14}$ Los objetos cobran sentido en el instante en que son denominados, sin que exista una previa captación intelectual que los com-prehenda. "La denominación de los objetos no viene luego del reconocimiento, es el mismísimo reconocimiento". ${ }^{15}$

Si el cuadro pintado es una expresión configurada según el lenguaje artístico podemos considerar que la obra de arte consuma un pensamiento, establece un sentido, crea un mundo... sin necesidad de que para entender la propuesta creativa que él nos presenta tengamos que pasar por un proceso de elaboración intelectual de su contenido. La comprensión se efectúa al nivel de las intenciones de mi cuerpo: comprender significa ser capaz de colocar mi cuerpo en la disposición o en la intencionalidad que la palabra o el cuadro requieren de nosotros; en otras palabras, en el mundo que la palabra o el cuadro despiertan. Formulado así parece que estamos ante una concepción del lenguaje digna de alguno de aquellos filósofos analíticos posteriores que destacarán el carácter performativo de los actos comunicativos.

\section{Reflexión teórica de Cézanne}

Pese a las escasas observaciones que Cézanne nos ofrece sobre su propia pintura todas ellas son de un elevado valor y delimitan con claridad la posible estética que hubiese escrito sobre sí mismo. La fuente fundamental que empleamos para la elaboración de este apartado son las cartas que el pintor escribió durante su vida. ${ }^{16}$ Aunque las afirmaciones teóricas que contiene su correspondencia no son sistemáticas ni muy extensas permiten formarse algo más que una idea acerca de los objetivos y los métodos que pone en juego Cézanne en su hacer pictórico - nunca mejor empleado que aquí el infinitivo,

13 Se recupera aquí el problema expuesto por Husserl en el parágrafo $\$ 124$ de Ideas $I$ en torno a la relación entre expresión y sentido expresado. Allí defiende la idea de que la capa de sentido es recogida por la expresión sin ser modificada. La expresión es un fenómeno no productivo (E. Husserl, Ideas I, FCE, Madrid, 1985, p. 295-299). El problema es que esto debe ser conjugado con la idea de que la expresión produce la entrada en el reino de lo físico de la significación ideal. Véase al respecto la crítica de Derrida (J. Derrida, Márgenes de la filosofia, ed. Cátedra, Madrid, 1988, pp. 197-199).

14 M. Merleau-Ponty, Fenomenologia de la percepción, p. 195.

15 Op. Cit., p. 194.

16 P. Cézanne, Correspondencia, ed. La balsa de la Medusa, Visor, Madrid, 1991. Todas las cartas de Cézanne citadas a continuación pertenecen a esta obra. 
puesto que su pintura se centra precisamente en el propio proceso creativo antes que en la presentación de un cuadro como resultado-.

\subsection{El cuadro como un "todo" perceptivo}

Rilke es uno de los intérpretes de Cézanne que mejor expresa como el ordenamiento de las diferentes partes de los cuadros del pintor francés contribuye a la configuración de un todo armónico vibrante. En sus cartas encontramos las siguientes notas:

Como ya he escrito, todo se ha reducido a un asunto de la relación de los colores entre ellos: uno se contiene ante el otro, o se acentúa frente a él, o se acuerda de sí mismo [...] En este vaivén de mil influencias recíprocas, el interior del cuadro vibra, se eleva, cae sobre sí mismo y en ningún punto está quieto. ${ }^{17}$

El cuadro es un todo que surge de la relación activa de cada uno de los colores en su mezcla con los demás. Más allá de ser concebida como un conjunto de trazos singulares, la pintura es una cuestión del efecto global que resulta de su combinación. Esta concepción del hacer pictórico que podemos denominar "global" viene a coincidir con el ordenamiento según una lógica total de la percepción entendida por Merleau-Ponty. De igual forma que en la percepción ninguno de los elementos que se aparecen vale absolutamente por sí fuera de las relaciones que sostiene con los otros elementos del campo en el que se aparece, en el cuadro ninguna de las partes representa algo por sí misma, sino que necesita de la colaboración de las restantes para generar un sentido que va más allá de lo que ellas transmiten por separado.

\subsection{La pintura del fluir de la experiencia}

En la pintura de Cézanne juegan un papel principal el vaivén del color y la vibración del cuadro. En una de sus numerosas cartas a Zola Cézanne explica cuales son sus motivos pictóricos favoritos:

Al ir a Marsella, me acompañó Monsieur Gibert. Estas personas captan bien las cosas, pero tienen ojos de profesores. Al pasar por el ferrocarril, cerca de los campos de Alexis, se despliega un motivo asombroso por la parte de levante: Ste-Victoire y las rocas que dominan Beaurecueil. Yo le dije: "Qué motivo tan bello", y él respondió: "Las líneas se balancean demasiado". ${ }^{18}$

17 R. M. Rilke, Cartas sobre Cezanne, ed. Paidos estética, Barcelona, 1985, p. 59.

${ }^{18}$ Carta a Zola, $14-4-1878$, p. 214 de la edición castellana. 
Que Gibert considerase un problema la falta de determinación de las líneas apunta al hecho de que según la pintura tradicional el objeto que debía servir como motivo debía poder ser determinado con una precisión rigurosa. La fluidez de la montaña de Ste. Victoire se convertía a la mirada antiacadémica de Cézanne en un objetivo pictórico de enorme atractivo, pero no por su belleza o majestuosidad, como sucedería para un pintor tradicionalista. Su insistencia en pintar las líneas que se balancean del contorno de la montaña según la diferente iluminación del día y de la estación anual, repetida a lo largo de los numerosos cuadros que realizó sobre la montaña, manifiesta un intento de captar el flujo de la experiencia originaria de nuestra percepción. Otro objetivo de menor calibre que éste no merecería convertirse en motivo pictórico. Como dirá Merleau-Ponty: "Para todos los gestos que poco a poco construyen un cuadro no hay más que un sólo motivo, y éste es el paisaje en su plenitud absoluta - cosa que justamente Cézanne llamaba un motivo". ${ }^{19}$ Si un pintor de corte clasicista centra sus esfuerzos en recoger de una forma más o menos realista el resultado de la percepción, la montaña tal y como se le aparece, Cézanne va más allá y quiere pintar el proceso previo. Su pintura no pretende ser una distorsión posterior a aquello que se aparece, sino que busca el origen de esta aparición. Propiamente hablando la distorsión es considerar que el proceso perceptivo constituye objetos ya de entrada ahí terminados y dotados de la rigidez con la que terminan por presentarse a la mirada.

Pero no se trata de que la montaña de Ste Victoire sea el único objeto pictórico en el que "las líneas se balancean demasiado". Todos los cuadros de Cézanne recogen los motivos pintados bajo un cierto movimiento fluido, incluso cuando se dedica a pintar algo tan estático como una naturaleza muerta. La peculiar reivindicación merleau-pontiana del "todo fluye" de Heráclito es recogida por Cézanne en su intento de pintar las cosas tal y como se aparecen en su fluidez originaria y no como objetos fijados y cosificados. Las naturalezas muertas de Cézanne cobran vida a través de una cierta latencia interna del color que desborda los contornos de los objetos, porque los contornos son en sus cuadros el resultado de la latencia interna de los colores, el producto de su fluir, y nunca límites impuestos desde el exterior. Cézanne se reconoce en uno de los personajes de la novela de Honoré de Balzac Chef-d'oeuvre inconnu. ${ }^{20}$ Este personaje, Frenhofer, también es pintor, y a través de su afirmación de que no existen contornos en sí, sino solamente transiciones oscilantes, le descubre a Cézanne la tarea infinita de pintar las cosas en el estado de vibración con el que existen al nivel de la experiencia originaria. Cézanne despreciará todos aquellos paisajes que tradicionalmente han sido escogidos como modelos para el aprendizaje del "buen pintar", porque en ellos las líneas

19 "La duda de Cézanne" en Sentido y sinsentido, ed. Península, Barcelona, 1977, p. 44.

${ }^{20}$ Hay traducción castellana: H. Balzac, La obra maestra desconocida, ed. Visor, Madrid, 2001. 
se ofrecen resaltando de una forma excesiva, cuando la propia naturaleza se muestra como tal sólo en su fluir ante la mirada:

Es esta una zona atemperada. La altitud de las colinas de este lugar es muy grande. El lago, en este lugar limitado por dos bocas, parece prestarse a los ejercicios lineales de jóvenes señoritas. No cabe duda de que esto es naturaleza; pero una naturaleza más bien como nos enseñaron a verla en los álbumes de las jóvenes viajeras. $^{21}$

Cézanne no atiende a la línea, no cree en el boceto que fija con trazos seguros los contornos de las figuras para luego rellenarlas con color. Este proceso no le puede parecer más que un intento de dominación y falsificación de la fuerza originaria con que brota las cosas en su estado natural, bruto si se quiere. Critica fervorosamente aquella pintura que marca los contornos con trazos negros fuertes y considera este procedimiento como un "defecto que hay que combatir con todas nuestras fuerzas. Ahora bien, la naturaleza consultada nos ofrece los medios de alcanzar este objetivo". ${ }^{22}$ Es la propia naturaleza la que rehuye esta forma de ser pintada, porque no se nos ofrece primariamente como delimitada por líneas, por unos contornos rígidos, sino a través de una experiencia originaria de fluidez.

\subsection{Motricidad del ojo ante el cuadro. Los colores en la pintura}

La cita de Merleau-Ponty en torno a la profunda interrelación entre el ojo y el objeto percibido que recogíamos en el apartado 1.3 de este artículo, podría muy bien haberse inspirado en el siguiente pasaje de Cézanne:

Para realizar progresos no hay nada como la naturaleza; el ojo se educa a su contacto. Se torna concéntrico a fuerza de mirar y de trabajar. Quiero decir que, en una naranja, una manzana, una bola, una cabeza, siempre hay un punto culminante; y este punto - a pesar del efecto terrible: luz y sombra, sensaciones cromáticas - es siempre lo que está más cerca de nuestro ojo; los bordes de los objetos huyen hacia un centro colocado en nuestro horizonte. ${ }^{23}$

El objeto, por así decir, efectúa un reclamo al ojo y apela directamente a su actividad llegando incluso a modificar su manera de percibir. Ambos se constituyen en una relación recíproca. La actividad del ojo es el fondo que necesariamente debe estar ahí con anterioridad sobre el que el objeto hace presa y puede ser entonces percibido. Simultáneamente el objeto despierta o

21 Carta a Joachim Gasquet, 21-6-1896, p. 316.

22 Carta a Émile Bernard, 23-10-1905, p. 391.

${ }^{23}$ Carta a Émile Bernard, 25-6-1904, p. 377. 
reclama la atención del ojo a través de sus colores, constituye un horizonte hacia el que el ojo tiene que apuntar. Todo objeto visual hace una llamada a nuestra capacidad de percepción provocando una vibración de sensaciones que con-mueve la capacidad motriz de nuestro cuerpo. Esto es evidente en ciertos casos clave de contemplación como la percepción mediante la que admiramos un paisaje, donde lo percibido comienza en la visión pero despierta un fondo motriz que va claramente más allá, nos llega a situar en una cierta disposición conjunta más amplia que la mera recepción de una imagen.

Esta misma defensa de un todo previo se hace patente cuando Cézanne reflexiona acerca de las relaciones entre luz y color. Cézanne considera que a través del color se hace posible la presencia de la luz y del aire o, en otras palabras, que la luz y el aire son variaciones detectadas dentro de un campo de percepción donde lo primario es el color. El color es un momento primario de la percepción absolutamente anterior a los objetos constituidos como unidades separadas que se configuran mediante él. No existe ningún vacío en el campo perceptivo, sino que aquello considerado habitualmente como lo más inaprehensible - el aire o la luz han sido normalmente interpretados como huecos - se aparece como el resultado de una serie de variaciones de un fondo que es color: no son elementos constitutivos autónomos, no ocupan un espacio por sí mismos, sino que deben ser pintados y recogidos a través de un algo que es el color. Encontramos por lo tanto aquí un vínculo no casual entre las teorías de Merleau-Ponty y Cézanne, en la medida en que ambos descubren cuán profunda es la relación entre la luminosidad y el color. Cézanne afirma que el sol es un gran mago que armoniza los colores para que configuren una sinfonía equilibrada; es el elemento mágico que da valor a la mezcla de colores ya preexistente al iluminarlos.

\subsection{La pintura de Cézanne como renuncia a los cánones intelectua- listas de la academia}

En contraste a otros artistas de su generación Cézanne reniega continuamente de la posibilidad de dedicarse concienzudamente a desarrollar un proyecto de autoesclarecimiento teórico de su técnica pictórica. Frente a ello se reafirma siempre en su papel de puro pintor. En claro contraste con aquellos pintores que pretenden fundamentar su hacer práctico-artístico sobre una determinada concepción estética Cézanne insiste en que hay una profunda contraposición entre la contemplación, que es la esencia de la vida del pintor, y el pensamiento, que habitualmente no constituye más que una carga pesada e impuesta desde el exterior a aquello que debe ser apreciado únicamente en su mostrarse natural. "Pero yo siempre vuelvo a lo mismo: el pintor debe con- 
sagrarse por entero al estudio de la naturaleza y tratar de realizar cuadros que sean una enseñanza. Las habladurías sobre el arte son prácticamente inútiles". ${ }^{24}$

Los intelectuales son considerados una ralea cuya compañía es tan odiosa que difícilmente puede ser aceptada. Después de haber leído un libro sobre su pintura responde a la solicitud del autor para que manifieste su opinión acerca del mismo criticando cualquier tipo de teoría como mera y vana especulación. ${ }^{25}$ Si Cézanne acepta algún tipo de reflexión teórica en torno a la pintura es siempre resaltando que ésta no puede apartarse lo más mínimo de una cierta naturaleza, de forma que no se pierda en ningún momento el contacto y la intuición que apuntan a ésta. Incluso las enseñanzas que los grandes maestros puedan aportar deben ser superadas a través de la liberación de los instintos artísticos que cada pintor lleva dentro de sí. Cualquier maestro no puede ser más que un orientador que permita descubrir por uno mismo "el sentimiento de la naturaleza". ${ }^{26}$

La pintura de Cézanne gira en torno a un intento denodado, casi infantil, por pintar esta naturaleza de forma cada vez más perfecta. Se trata de un intento en toda regla por descubrir lo primitivo; es decir, la naturaleza vista por una mirada ateórica y libre todavía de la interpretación ejercida por las categorías de lo cotidiano. El pintor debe reconducir su mirada a aquellas impresiones primeras, confusas y dinámicas que le ofrecen los objetos, tal y como se supone que hace la mirada de un niño recién nacido en sus primeros contactos con lo real: "Cuando vuelva a Aix iré a darte un abrazo. Por el momento, sigo buscando la expresión de estas sensaciones que aportamos al nacer". ${ }^{27}$

Cézanne quiere recuperar esta hipotética visión primitiva y rescatarla en toda su pureza por dos motivos principales: primero, porque se trata de aquella visión particular que nos caracteriza a cada uno de nosotros, nuestra manera de percibir las cosas antes de que la cotidianidad o la norma social codifique lo que se presenta en la percepción; y segundo, porque ella nos pone en verdadero contacto con lo que sean las cosas, permite descubrir la naturaleza más originaria de las cosas. Una y otra vez insiste en la necesidad de liberar el propio temperamento en contacto con la naturaleza, en dejar que afloren las sensaciones que aquella nos provoque y pintarlas sin amedrentarse del resultado y de la posible incomprensión de quienes apreciarán en el futuro la obra pintada. Frente a la elegancia cursi de la pintura escolar fundamentada en las líneas Cézanne quiere presentar la violencia de una pintura desmesurada que aspira a recoger la physis en su brotar originario.

24 Carta a Émile Bernard, 12-5-1904, p. 374.

25 Carta a Charles Camoin, 28-1-1902, pp. 348-9

26 Carta a Charles Camoin, 9-12-1904, p. 380.

27 Carta a Henri Gasquet, 3-6-1899, p. 338. 


\section{Merleau-Ponty y Cézanne: búsqueda de la experiencia originaria más allá de lo humano. Conclusiones}

Merleau-Ponty le dedica en exclusiva a Cézanne uno de los capítulos de Sentido y sinsentido titulado "La duda de Cézanne" ${ }^{28}$ De entrada debe señalarse que el título del capítulo no parece demasiado acertado. Puede ganar sentido si se quiere expresar con él que en un determinado momento Cézanne no comprende el sentido de su pintar e incluso llega a plantearse si toda su creación no es más que el resultado de un defecto fisiológico de su mirada. Más allá de esto parece que no se puede afirmar que Cézanne haya vacilado en su proceder pictórico, puesto que en ningún momento de su vida deja de pintar durante una larga temporada y las variaciones en su estilo, aún siendo notables, no cesan de seguir un mismo hilo común. No hay algo así como enormes crisis que corten el ritmo de su trabajo. Antes que de una duda de lo que se trata en cada uno de sus cuadros es de un "trabajo eterno" o de una "lucha" por acercarse a lo originario de la experiencia.

Merleau-Ponty insiste en que Cézanne habría intentado que cada una de las deformaciones de la perspectiva que aparecen en sus cuadros se anulasen para generar una disposición de conjunto donde se aparece "un orden naciente, un objeto que está apareciendo, que se está aglomerando ante nuestros ojos". ${ }^{29}$ El contorno de los objetos es delimitado a través de numerosísimos trazos, de forma que es sólo pasando de un trazo a otro como se genera un contorno que no cesa jamás de ser algo en constante germinación y nacimiento. Tanto para el fenomenólogo como para el pintor la naturaleza es por definición un fenómeno antilineal. Pese a las apariencias el mundo es un conjunto formado primariamente por una serie de transiciones inestables, cuya experiencia verdadera no deja de ser un continuo manar que no termina de fijarse de forma definitiva.

En la pintura académica-"humana" el principal recurso son unos trazos que están ahí claramente dispuestos a ser percibidos merced a una cierta familiaridad con la que se muestran a nuestra percepción. Merleau-Ponty insiste en el carácter inhumano de la pintura de Cézanne. Cada cuadro es una propuesta para entrar en el mundo de lo sensible, de manera que incluso un rostro debe ser pintado en un proceso deshumanizador como un objeto sensible más. $\mathrm{Su}$ pintura revela el fondo de naturaleza inhumana o experiencia originaria sobre el que se instala el ser humano. Tomando la expresión de Ortega, deshumanización del arte significa aquí el incansable anhelo del humano Cézanne por sobrepasar las formas y categorías humanas para pintar al hilo de una intuición divina que va más allá de cualquier categorización antropomórfica para 
descubrir la pasividad o sedimento experiencial originario ${ }^{30}$. El propio pintor reconoce la dificultad y la extrema lentitud con que progresa el buscado descenso a la naturaleza, dando en ocasiones muestras de desfallecimiento y de cansancio. La insatisfacción constante que sus obras le provocan una vez finalizadas le impulsa a retomar de nuevo el pincel y comenzar un nuevo intento por plasmar las cosas justo en el instante anterior a aquel en el que se convierten en objetos. Usando una expresión que tanto le agrada a la filosofía francesa del siglo XX pintar aquello que precede a los objetos en el instante que dura un guiño de ojo en que nos dirigimos a ellos. En todo caso cabe resaltar aquí que no se trata de un proceso deshumanizador caprichoso como quizás se le ha reprochado en ocasiones al cubismo y a la pintura abstracta posteriores. Más bien se intenta ir más allá de lo habitualmente considerado humano para descubrir algo humano en un sentido mucho más originario. La naturaleza se convierte en las manos de Cézanne en Naturaleza: en una de sus cartas escribe la palabra con una $\mathrm{N}$ mayúscula inicial ${ }^{31}$ puesto que su Naturaleza no es la naturaleza que habitualmente observamos en nuestra existencia cotidiana, sino que consiste en el sentido profundo con el que la Naturaleza se le muestra a un pintor que se haría entonces con toda justicia acreedor del titulo "pintor originario".

Carbone recoge en una nota a pie de página unas reflexiones de Lyotard de la obra Des dispositifs pulsionnels donde este discrepa de Merleau-Ponty. ${ }^{32}$ Según Lyotard el fenomenólogo francés es deudor del racionalismo cartesiano al considerar erróneamente que por debajo del desorden pictórico con el que aparece el mundo en sus cuadros Cézanne pretendería mostrar el verdadero orden de lo sensible. Para Lyotard el pintor no pretende más que llevar a cabo una construcción de un tipo de experiencia que de ninguna forma aspira a ser considerada como la más natural o la más originaria. En nuestra opinión Merleau-Ponty lleva razón en este punto. Cézanne pretende acercarse a la naturaleza tal como él la vive, pero no para ofrecer su propia visión subjetiva de algo natural - uno idéntico para todos, sino porque considera que la esencia de esa naturaleza sólo se le puede ofrecer a cualquier individuo a través de su propia experiencia originaria. La afirmación de que Merleau-Ponty recurre a un en-sí cartesiano no parece muy sostenible desde el momento en que toda su crítica se dirige a mostrar como el en-sí es siempre algo para un sujeto. Cuando Cézanne reniega de lo humano, debemos entender que esto humano de lo que se aparta es de la visión de las jóvenes señoritas que aprenden a

30 Piénsese también en la importancia que cobra el concepto de "síntesis pasiva" en la filosofia del Husserl posterior a las Ideas (E. Husserl, Analysen zur passiven Synthesis. Aus Vorlesungs- und Forschungsmanuskripten 1918-1926. Den Haag, Martinus Nijhoff, Husserliana, Band XI).

${ }^{31}$ Carta a Charles Camoin, 13-9-1903, p. 368.

${ }^{32}$ Carbone, M., Ai confini dell'esprimibile, Guerini Studio, Milano, 1990, p. 26. 
pintar en la academia. ${ }^{33}$ Se trata de renegar de una visión cotidiana y manida de las cosas - aquella en que las cosas son utensilios a-la-mano - para penetrar en su naturaleza de forma mucho más profunda.

La misma contradicción-relación existente entre el cuerpo y las cosas en el caso de Merleau-Ponty se hace patente en la pintura de Cézanne. Las cosas se dan sólo para un cuerpo, pero aspiran a ser algo en-sí diferente del cuerpo. En el pintor encontramos un desgarramiento interno que nunca podrá ser reconciliado, que nunca se clausurará en una síntesis superadora y reconfortante: Cézanne, que es humano, quiere pintar lo suprahumano, la naturaleza libre de las estructuras fundamentales con las que la percibimos. "Y es por eso que los paisajes de Cézanne son 'los de un pre-mundo en el que aún no había hombres' ". ${ }^{34}$ Pero es innegable que pese a que su mirada pictórica pretenda trascender las categorías perceptivas tradicionales, Cézanne también es un ser humano. Así se hace patente que todo mundo tiene sentido tan sólo para un sujeto, porque "solamente un hombre puede ser capaz de esta visión que va hasta las raíces, más allá de la humanidad constituida". ${ }^{35} \mathrm{Si}$ se habla en términos de una dicotomía entre lo humano y lo inhumano, habrá que explicitar qué es eso inhumano que se quiere pintar. Ante todo se trata de superar el carácter cartesiano del que hablaba Lyotard. En el primer apartado de este trabajo se podía comprobar como Merleau-Ponty intentaba partir de un punto donde el sujeto y el objeto todavía no estaban separados. Su interpretación de Cézanne se hace partícipe de esta idea y pretende mostrar como este mismo punto de partida único opera en la peculiar concepción de la pintura del maestro francés:

Cézanne no creyó tener que escoger entre sensación y pensamiento, ni tampoco entre caos y orden. No ha querido separar las cosas fijas que aparecen ante nuestra mirada y su manera fugaz de mostrársenos, ha querido pintar la materia dándose forma a sí misma, el orden que nace de una organización espontánea. No ha marcado ninguna ruptura entre "los sentidos" y "la inteligencia", sino entre el orden espontáneo de las cosas percibidas y el orden humano de las ideas y las ciencias. ${ }^{36}$

La verdadera dicotomía se ofrece entre lo científico y lo natural, entre las construcciones de sentido de tipo matemático, formal y el mundo de la vida que las sostiene, por mucho que las primeras las hayan desplazado. La ruptura que la perspectiva geométrica ofrece debe ser asentada sobre un ámbito anterior donde el dualismo entre representado y representante, objeto y sujeto, no es captable. Las mismas dificultades que la pasividad le ofrece

33 Véase nota 18 de este estudio.

34 Op. Cit, p. 336.

35 M. Merleau-Ponty, La duda de Cézanne, p. 43. 
a Merleau-Ponty las habría encontrado Cézanne en su pintura: no es posible una reapropiación absoluta de la experiencia, porque siempre queda un primer sedimento en cada nuevo acto de apropiación que es intangible, que no puede ser llevado a la expresión. Sobre este sedimento se apoya y a partir de él nace la mirada humana. Tanto el pensamiento de Husserl como el de Merleau-Ponty se caracterizan por una invitación continua a recuperar las experiencias originarias que subyacen a cada una de nuestras intuiciones con el ánimo de evitar todo falseamiento en su descripción. Habría en la base de la filosofía del fenomenólogo francés y en la base de la pintura de Cézanne un intento titánico compartido: realizar una eterna re-descripción que busca purificarse eternamente para acercarse más y más a las fuentes de la experiencia originaria.

Consideremos por un momento que el lenguaje artístico no deja de ser un tipo de lenguaje, colocándose al lado del lenguaje verbal. Merleau-Ponty realiza una aproximación a lo que podríamos considerar a muy grosso modo la filosofía del lenguaje del segundo Heidegger, aún teniendo en cuenta que en el caso de Heidegger este fenómeno es especialmente relevante en el caso de la palabra poética. La palabra pasa de ser un utensilio de expresión a convertirse en el lugar donde nace la verdad. Los vocablos nombran según una relación que no es externa a lo nombrado y que consigue fijar la naturaleza de las cosas sin someterlas a ninguna violencia. De igual forma, el pintor logra acercarse al origen de las cosas cuando pinta los objetos exactamente según aquella forma "confusa" en la que a él se le aparecen: "El pintor toma y convierte justamente en objeto visible aquello que sin él quedaría encerrado en la vida aislada de cada conciencia: la vibración de las apariencias que constituye el origen de las cosas"37. Tanto la palabra del poeta como el pincel del pintor crean un mundo, permiten que se aparezcan las cosas, traen a la luz y desocultan el ser más allá de ser meras traducciones de un sentido anterior. Antes de la expresión no se puede afirmar que haya existido algo, sino una "vaga fiebre". ${ }^{38}$

La palabra griega physis procede de un verbo que significa "brotar, surgir"; la noción griega de naturaleza connota una cierta actividad, una cierta capacidad para mostrarse. Parece que las dos figuras que se han estudiado no proponen al fin ninguna otra cosa que recuperar el sentido griego del término naturaleza. Ambos quieren captar el fundamento de nuestra experiencia, la base sobre la que se alza nuestra percepción tal y como esta se nos muestra antes de cualquier categorización científica. Tanto la fenomenología de Merleau-Ponty como la pintura de Cézanne serían manifiestos a favor de la re-creación de nuestra experiencia de un mundo originario asfixiado por la cotidianidad. Las tendencias predominantes en la estética contemporánea apuntan a la defensa de la belleza episódica, plástica, reciclable. En palabras de Peter Handke: "La queja se convierte en algo posible: la cotidianeidad se ha vuelto 
mala. Existe sólo la belleza episódica, triste, que rodea las cosas hechas, y ésta ya no es algo en cuyo regreso podamos confiar y, por tanto, sigue siendo irreal" ${ }^{39}$ Por su parte, en el ámbito de la filosofía es objeto de burla cualquier intento de fundamentación argumentativa rigurosa. Bajo el lema, que en la mayoría de las ocasiones suena a excusa, de que el tiempo de los grandes relatos se ha terminado, ni siquiera se respetan relatos filosóficos seguramente no tan grandes ni espectaculares como los de un cierto pasado pseudo-imperial de la filosofía académica pero todavía valiosos. ${ }^{40}$ Quizás recuperar algo de tiempo para el pathos de la reflexión radical de la fenomenología o para la pintura de Cézanne puedan ser un buen antídoto contra esta situación.

\begin{abstract}
This paper tries to clarify the coincidence between some of the main features of the characterization of perception in the phenomenology of Merleau-Ponty (Phenomenology of Perception) and the picture technique of Cézanne. Although placed in different work areas, indeed, the reflection about the perceptive act and the process of pictorical creation, there is an inspirational shared basis: Merleau-Ponty's notion of "original experience" goes parallel to Cézanne's understanding of the painting as a the original appearing of the things so as they should appear to a glaze that goes beyond the objectivating categories of every daily, normal perception.
\end{abstract}

${ }^{39}$ P. Handke, La doctrina del Sainte Victorie, Alianza Tres, Madrid, 1985, p. 67.

40 J-F. Lyotard, La condición postmoderna, ed. Cátedra, Madrid, 1998. 